\title{
THE STATE OF CHOLESTEROL LEVEL IN HYPERTENSION IN SADANANYA HEALTH CENTER
}

\author{
Irpan Ali Rahman', Endrian Mulyadi Justitia Waluyo², Shafira Aisyah Darmawan ${ }^{3}$ \\ ${ }^{1}$ Prodi S1 Keperawatan, STIKes Muhammadiyah Ciamis \\ Email: van.vinnot@gmail.com \\ ${ }^{2}$ Prodi S1 Keperawatan, STIKes Muhammadiyah Ciamis \\ email: endrian1987@gmail.com
}

\begin{abstract}
ABSTRAK
Hypertension is an increase in systolic blood pressure above $140 \mathrm{mmHg}$ and diastolic blood pressure above $90 \mathrm{mmHg}$. The number of hypertension sufferers has increased each year, in 2015 it reached 19,552, in 2016 it reached 24,750 and in 2017 it reached 38,057. In 2017 there were 115 hypertensive patients recorded in the report book that checked their health at the Sadananya Health Center. One of thecauses of the high incidence of hypertension is cholesterol caused by the consumption of inappropriate food. One of the laboratory examinations to support hypertension diagnosis is blood cholesterol examination which can show excess cholesterol which makes hypertension difficult to control. To know the description of total cholesterol levels in hypertensive patients at the Sadananya Health Center. Quantitative descriptive, the population in this study were people with hypertension at the Sadananya Health Center. Sampling with accidental sampling, as many as 30 respondents. The cholesterol examination method used is CHOD-PAP. The results showed that blood pressure in respondents all had high blood pressure, namely $>140 / 90 \mathrm{mmHg}$ (100\%), a high cholesterol level of 24 respondents (80\%), blood pressure 140-150 who had high cholesterol as many 13 respondents, blood pressure 160-170 who had high cholesterol as much 6 respondents, blood pressure $>180$ who had high cholesterol as much 5 respondents. This study concludes that hypertensive clients have more high total cholesterol levels, which is as much as $80 \%$ and normal 20\%. More hypertensive patients have high total cholesterol levels, which are $80 \%$ and $20 \%$ normal.
\end{abstract}

\section{Keywords : Cholesterol, Hypertension}

\section{PENDAHULUAN}

Hipertensi merupakan kondisi dimana seseorang mempunyai tekanan darah sistol (Sistolic Blood Pressure) lebih atau sama dengan $140 \mathrm{mmHg}$ dan tekanan darah diastol (Diastolic Blood Pressure) lebih atau sama dengan $90 \mathrm{mmHg}$ sesuai kriteria WHO (Firmansyah nd, 2017). World Health Organization (WHO) menunjukkan bahwa sekitar 972 juta orang atau 26,4\% di dunia mengidap hipertensi dan akan terus meningkat menjadi 29,2\% pada tahun 2025 . diperkirakan jumlah penderita hipertensi akan meningkat menjadi 1,6 milyar menjelang tahun 2025. Kurang lebih 10-30\% penduduk dewasa di hampir semua negara mengalami penyakit hipertensi, dan sekitar $50-60 \%$ penduduk dewasa dapat dikategorikan sebagai mayoritas utama yang status kesehatannya akan menjadi lebih baik bila dapat dikontrol tekanan darahnya (Pengetahuan et al., 2016).

Salah satu penyebab kematian di dunia, terdapat 7 juta orang meninggal dunia akibat

DOI : https://doi.org/10.51544/jmn.v4i2.1543

(C) 2021 Jurnal Mutiara Ners. This is an open accessarticleunder the CC BY-SA license Website : http://e-journal.sari-mutiara.ac.id/index.php/NERS/index 
hipertensi. Prevalensi hipertensi di dunia sebesar 26,4\% yang terdiri dari populasi usia dewasa (Nugraha \& Badrawi, 2018).

Hasil dari Riset Kesehatan Dasar (RisKesDas) prevalensi hipertensi di Indonesia pada tahun 2013 sebesar 28,5\%, sedangkan prevalensi hipertensi di Indonesia pada tahun 2017 meningkat menjadi 30,9\% menurut hasil survei Indikator Kesehatan Nasional. Prevalensi di Indonesia di tentukan berdasarkan pengukuran tekanan darah pada penduduk dengan usia $\geq 18$ tahun(KemenKes RI, 2017). Berdasarkan laporan Dinas Kesehatan Kabupaten Ciamis jumlah penderita hipertensi tiap tahunnya terjadi peningkatan, pada tahun 2015 mencapai 19,552 penderita, tahun 2016 mencapai 24,750 penderita dan tahun 2017 mencapai 38,057 penderita (Dinkes Ciamis 2017). Dari 37 Puskesmas di Kabupaten Ciamis, Puskesmas Sadananya memiliki angka tertinggi ke dua kasus hipertensi setelah Puskesmas Tambaksari. Terdapat 115 pasien hipertensi tercatat dalam buku laporan yang memeriksakan kesahatannya di Puskesmas Sadananya.

Kolesterol merupakan zat berlemak yang diproduksi oleh hati. Kolesterol dapat ditemukan diseluruh tubuh dan berperan penting terhadap fungsi tubuh sehari-hari (Soebroto, 2010). Menurut (Soebroto, 2010) kolesterol dalam tubuh mempunyai fungsi yang penting, diantaranya:

Membantu hati menghasilkan empedu, untuk mencerna lemak, Membuat kelenjar adrenal dan hormon seks, Membantu tubuh membuat vitamin D, Membuat lapisan luar atau dinding sel, Membawa lemak keseluruh tubuh memalui peredaran darah.

Jika jumlah lebih banyak dari yang bisa diproses dan digunakan oleh tubuh, kolesterol bisa disimpan dalam dinding pembuluh darah, dimana kemudian menjadi berbahaya bagi tubuh. Kenaikan kadar kolesterol yaitu angkanya lebih dari 200 $\mathrm{mg} / \mathrm{dL}$, merupakan faktor risiko tunggal yang paling penting pada penyakit jantung coroner (Setiawan \& Felix, 2014). Klasifikasi kolesterol total menurut NCEP- ATP III (mg/dL) normal $<200 \mathrm{mg} / \mathrm{dL}$, tinggi

$>240 \mathrm{mg} / \mathrm{dL}$. Menurut Hasdianah \& Sentot, (2014) ada beberapa faktor yang menyebabkan kadar kolesterol dalam darah menjadi tinggi, yaitu usia, jenis kelamin, pola makan, berat badan, kurang bergerakdan penyakit tertentu.

Urgensi dalam penelitian ini adalah Mengetahui Kadar Kolesterol Total pada Klien Hipertensi.

Kebaruan dalam penelitian ini terletak pada tahun penelitian, tempat dan populasi dalam penelitian ini yaitu klien hipertensi yang secara kebetulan sedang berkunjung Ke Puskesmas Sadananya Kabupaten Ciamis dan instrumen penelitian yang di gunakan adalah lembar observasi, Instrumenpenelitian untuk mengukur tekanan darah menggunakan alat Spigmomanometer dan stetoscope, kemudian dilakukan pemeriksaan kolesterol di labolatorium dengan menggunakan metode CHOD-PAP.

\section{METODE PENELITIAN}

Penelitian ini bertujuan untuk menegetahui gambaran kadar kolesterol total pada hipertensi di Puskesmas Sadananya Kabupaten Ciamis. penelitian ini menggunakan rancangan deskriptif kuantitatif. Populasi pada penelitian ini sebanyak 115 responden. Teknik pengambilan sampel yang digunakan adalah teknik Accidental Sampling, dengan pengambilan sampel yang memenuhikriteria inklusi dan eklusi sebanyak 30 responden. Analisa pada penelitian ini menggunakan Microsoft excel 2013.

Instrumen penelitian untuk mengukur tekanan darah menggunakan alat Spigmomanometer dan stetoscope, kemudian dilakukan pemeriksaan kolesterol di labolatorium dengan menggunakan metode CHOD-PAP. 


\section{HASIL}

Distribusi frekuensi responden berdasarkan karakteristiknya meliputi usia,

jenis kelamin, pola makan diperoleh gambaran sebagai berikut :

\begin{tabular}{ccc}
\multicolumn{3}{c}{$\begin{array}{c}\text { Tabel 1. Distribusi Frekuensi } \\
\text { Karakteristik Responden } \\
\text { Berdasarkan Usia }\end{array}$} \\
\hline Usia & F & $(\%)$ \\
\hline 35-44 Tahun & 2 & 6,67 \\
45-54 Tahun & 7 & 23,33 \\
55-64 Tahun & 11 & 36,67 \\
$>65$ & 10 & 33,33 \\
\hline Jumlah & 30 & $100 \%$ \\
\hline
\end{tabular}

Tabel 2. Distribusi Frekuensi

Karakteristik Responden

Berdasarkan Jenis Kelamin

\begin{tabular}{lcc}
\hline \multicolumn{1}{c}{ Jenis kelamin } & F & $(\%)$ \\
\hline Perempuan & 29 & 97 \\
Laki-Laki & 1 & 3 \\
\hline Jumlah & 30 & 100 \\
\hline
\end{tabular}

Tabel 3.Distribusi Frekuensi

Karakteristik Berdasarkan Kebiasaan Pola Makan

\begin{tabular}{ccc}
\hline $\begin{array}{c}\text { Kebiasaan konsumsi } \\
\text { makanan berlemak }\end{array}$ & $\mathrm{F}$ & $(\%)$ \\
\hline Setiap hari & 18 & $60,0 \%$ \\
Jarang & 12 & $40,0 \%$ \\
Tidak pernah & 0 & 0 \\
\hline Jumlah & 30 & $100,0 \%$ \\
\hline
\end{tabular}

\section{Tabel 4. Distribusi Frekuensi Karakteristik Responden Berdasarkan Tekanan Darah}

\begin{tabular}{ccc}
\hline Tekanan Darah & $\mathrm{F}$ & $(\%)$ \\
\hline $\begin{array}{c}\text { Tinggi } \\
(>140 / 90 \mathrm{mmHg})\end{array}$ & 30 & $100 \%$ \\
\hline Jumlah & 30 & $100 \%$ \\
\hline
\end{tabular}

Tabel 5. Distribusi Frekuensi Karakteristik Responden Berdasarkan Kadar Kolesterol

\begin{tabular}{ccc}
\hline Kadar Kolesterol & F & $(\%)$ \\
\hline Tinggi $(>200 \mathrm{mg} / \mathrm{dL})$ & 24 & 80 \\
Normal $(200 \mathrm{mh} / \mathrm{dL})$ & 6 & 20 \\
Rendah $(<200 \mathrm{mg} / \mathrm{dL})$ & 0 & 0 \\
\hline Jumlah & 30 & 100 \\
\hline
\end{tabular}

Tabel 6.Kadar Kolesterol pada Hipertensi di Puskesmas Sadananya Kabupaten Ciamis

\begin{tabular}{|c|c|c|c|c|}
\hline \multirow[t]{2}{*}{ TD } & \multicolumn{3}{|c|}{ Kolesterol } & $(\%)$ \\
\hline & Tinggi & Normal & Rendah & \\
\hline $140-159$ & 13 & 4 & & 56.7 \\
\hline $160-170$ & 6 & 2 & & 26.7 \\
\hline$>180$ & 5 & $\underline{6}$ & & $\underline{16.7}$ \\
\hline Jumlah & 24 & $\underline{6}$ & & $\underline{100}$ \\
\hline
\end{tabular}

Berdasarkan table 1 frekuensi usia paling banyak usia 55-64 tahun sebanyak 11 responden $(36,67 \%)$, Berdasarkan table 2 frekuensi jenis kelamin, hasil terbanyakyaitu perempuan sebanyak 29 responden (97\%), Berdasarkan table 3 Frekuensi pola makan responden memiliki kebiasaan mengkonsumsi makanan berlemak setiaphari yaitu sebanyak 18 responden (60\%), Berdasarkan Tabel 4 frekuensi tekanan darah pada responden semuanya memilikitekanan darah tinggi yaitu >140/90 $\mathrm{mmHg}(100 \%)$, Berdasarkan table 5 bahwa dari 30 responden, frekuensi karakteristik berdasarkan kadar kolesterol didapatkan hasil terbanyak yaitu kadar kolesterol tinggi sebanyak 24 responden (80\%). Berdasarkan table 6 yang tekanan darah 140-150 yang memiliki kolesterol tinggi sebanyak 13 responden, normal 4 responden.

DOI : https://doi.org/10.51544/jmn.v4i2.1543

(C) 2021 Jurnal Mutiara Ners. This is an open accessarticleunder the CC BY-SA license Website : http://e-journal.sari-mutiara.ac.id/index.php/NERS/index 


\section{PEMBAHASAN}

Hasil penelitian didapatkan bahwa 30 responden memiliki riwayat hipertensi yang memiliki tekanan darah $>140 / 90 \mathrm{mmHg}$. Endapan kolesterol dalam pembuluh darah menyebabkan penyempitan pembuluh darah, hal ini mengakibatkan aliran darahterganggu karena berkurangnya elastisitas pembuluh darah, untuk mengatasi gangguan ini jantung harus memompa darah lebih keras sehingga tekanan dalam pembuluh darah menjadi semakin tinggi (Soebroto, 2010).

Penelitian terbagi menjadi 4 kelompok usia yaitu usia 35-44 tahun, 45-54 tahun, 5564 tahun dan $>65$. Usia terbanyak terdapat pada usia 55-64 tahun dengan jumlah 11 responden $(36 \%)$. Untuk jenis kelamin, responden terbanyak yaitu perempuan sebanyak 29 responden $(96,7 \%)$, dan lakilaki sebanyak 1 responden $(3,3 \%)$.Sedangkan hasil frekuensi pola makan responden memiliki kebiasaan mengkonsumsi makanan berlemak setiaphari yaitu sebanyak 18 responden (60\%).

Berdasarkan hasil penelitian didapatkan hasil kadar kolesterol total pada hipertensi hasil terbanyak yaitu kadar kolesterol tinggi sebanyak 24 responden $(80 \%)$, kadar kolesterol yang tinggi dipengaruhi oleh umur, jenis kelamin dan pola makan. Ada beberapa kemungkinan alasan mengapa kadar kolesterol menjadi tinggi dan dapat juga dikendalikan, namun ada juga yang tidak dapat dikendalikan.

Selain itu faktor seperti jenis kelamin juga mempengaruhi peningkatan kolesterol dalam tubuh seperti pada table 2 didapatkan hasil terbanyak yaitu perempuan sebanyak 29 responden. Karena perempuan yang sudah mengalami menopause, akan mengalami tingkat kadar esterogen yang menurun sehingga memiliki risiko tinggi penyakit jantung. Sejalan dengan hasil penelitian terdahulu menurut Hasdianah \& Sentot, (2014) ada beberapa faktor yang menyebabkan kadar kolesterol dalam darah menjadi tinggi, antaralain usia dan jenis kelamin. Peningkatan kadar kolesterol dalam batas tertentu merupakan hal alami yang terjadi dalam proses penuaan.

Berdasarkan tabel.1 menunjukan usia terbanyak yaitu usia 55-64 tahun. Hal ini di karenakan perubahan komposisi tubuh akibat menua menyebabkan penurunanmassa tanpa lemak dan massa tulang, sedangkan massa lemak tubuh meningkat perubahan tersebut karena aktifitas beberapa jenis hormon yang mengatur metabolisme menurun sesuai dengan umur (Putri, Hariyono, \& Puspita, 2016).

Hasil penelitian ini sejalan dengan penelitian sebelumnya menurut Cooper Clinic, Dallas-USA dalam Putri et al, (2016) tentang pengaruh umur terhadap profil lemak darah pada laki-laki (2.000 orang) dan perempuan (589 orang) didapatkan bahwa kenaikan kolesterol total pada laki-laki seiring dengan bertambahnya umur. Kolesterol total dan LDL mengalami kenaikan laju kecepatan yang sama. Peneliti menyampaikan bahwa semakin tua seseorang semakin berkurangnya kemampuan atau aktifitas reseptor LDL-nya sehingga menyebabkan LDL darah meningkat dan mempercepat terjadinya penyumbatan arteri. Penyebab lainnya bahwa semakin tua seseorang makin banyak menderita obesitas atau persentase lemak tubuh naik.

Menurut Putri, Hariyono, \& Puspita (2016) pada penelitian sebelumnya menjelaskan bahwa faktor-faktor seperti umur, jenis kelamin, pola makan juga mempengaruhi peningkatan kolesterol dalam tubuh. Gemar makan makan makanan yang mengandung lemak tinggi akan menambah kadar kolesterol dalam darah. Dimana makanan makanan tersebut mengandung lemak jenuh yang dapat meningkatkan kadar kolesterol dalam tubuh karena Sumber kolesterol ada dua yaitu kolesterol eksogen 
yang bersal dari makanan yang kita makan sehari-hari, dan kolesterol endogen yang dibuat didalam sel tubuh terutama hati.

Orang yang paling berisiko memiliki kadar kolesterol tinggi adalah orang yang menerapkan pola makan yang mengandung kadar lemak jenuh yang tinggi. Lemak jenuh ditemukan pada daging, mentega, keju yang dapat meningkatkan kadar kolestrol LDL dalam darah. (Hasdianah \& Sentot, 2014).

Terdapat klien dengan hipertensi dengan kolesterol tinggi sebanyak 24 responden dan 6 responden normal. Hal tersebut dikarenakan responden yang memiliki hasil kadar kolesterol yang tinggi lebih sering mengkonsumsi makanan yang berlemak setiap hari dibandingkan dengan yang memiliki kolesterol normal dimana responden lebih bisa membatasi makanan yang berlemak.

\section{SIMPULAN}

Responden klien hipertensi lebih banyak memiliki kadar kolesterol total yang tinggi yaitu sebanyak 24 responden dan yang normal 6 responden.

\section{REFERENSI}

Anies. (2015). Kolestrol Dan Penyakit Jantung Koroner. Yogyakarta: ArRuzz Media.

Anisah, C., \& Umdatus, S. (2015). Gambaran Pola Makan Pada Penderita Hipertensi Rawat Inap Di Irna F RSUD Syarifah Ambami Rato Ebu Kabupaten Bangkalan Madura. Jurnal Keperawatan, 2(3).

Awan, H., \& Sulistyowati. (2015). Keperawatan Medikal Bedah 1. Jakarta: Ar- Ruzz Media.

Bumi, M. (2017). Berdamai Dengan Hipertensi. jakarta: Bumi Buku Merdeka.

Chitrayana, N., Feby, B., Lauren, Y., Rumawas, M. E., \& Kidarsa, V. B. (2014). Kepribadian Tipe A dan
Risiko Hipertensi pada Orang Dewasa. Kesmas: National Public Health Journal, 8(8), 380-385.

Crea, M. (2010). Hypertension. Jakarta: Medya.

Feryadi, R., Sulastri, D., \& Kadri, H. (2014). Hubungan Kadar Profil Lipiddengan Kejadian Hipertensi pada Masyarakat Etnik Minangkabau di Kota Padang Tahun 2012. Jurnal Kesehatan Andalas, 3(2), 206-211.

Firmansyah, M. R., \& Rustam. (2017). Hubungan Merokok dan Konsumsi Kopi dengan Tekanan Darah pada Pasien Hipertensi. Jurnal Kesehatan, 3(2), 263-268.

Firmansyah, R. S., Lukman, M., \& Mambangsari, C. W. (n.d.). FaktorFaktor yang Berhubungan dengan Dukungan Keluarga dalam Pencegahan Primer Hipertensi. 2017, 5, 197-213.

Gray, Et, \& Al. (2005). Lecture Notes Kardiologi (edisi 4). jakarta: Erlangga medical series.

Hasdianah, H., \& Sentot, S. (2014). Patologi \& Patofisiologi Penyakit (1st ed.). Yogyakarta: Nuha Medika.

Hernawan, T., \& Rosyid, F. N. (2017). Pengaruh Senam Hipertensi Lansia Terhadap Penurunan Tekanan Darah Lansia Dengan Hipertensi Di Panti Wreda Darma Bhakti Kelurahan Pajang Surakarta Totok, 10(1), 26-31.

Marliani, L., \& S, Tantan. (2007). 100 Question And Answer Hipertensi. Jakarta: Elex Media Koputindo.

Notoatmodjo,S. (2010). Metodologi Penelitian Kesehatan. Jakarta: Rineka Cipta.

Nugraha, G., \& Badrawi, I. (2018).Pedoman Teknik Pemeriksaan Laboratorium Klinik. Jakarta: Trans Info Media.

DOI : https://doi.org/10.51544/jmn.v4i2.1543

(C) 2021 Jurnal Mutiara Ners. This is an open accessarticleunder the CC BY-SA license 
Nursalam. (2013). Konsep dan Penerapan Metodologi Penelitian Ilmu Keperawatan. Jakarta: Salemba Medika.

Pengetahuan, P., Dan, S., \& Keluarga, D. (2016). TERHADAP DIET HIPERTENSI DI DESA HULU KECAMATAN PANCUR BATU TAHUN 2016 Staf Pengajar Fakultas Kesehatan Masyarakat Universitas Sumatera Utara Keywords : Knowledge , Attitude , Family Support , Implementation Hypertension Diet. Jurnal Mutiara Ners, 1, 73-80.

Pical, femmy imelia. (2011). Prevalensi Dan Determinan Hipertensi Di Posyandu Lansia Wilayah Jakarta Timur.

Priyadarshini, I. A. U. (2012). Prevalensi hipertensi dan kebiasaan merokok, konsumsi alkohol, serta konsumsi garam pada penduduk usia 20-59 tahun di wilayah kerja UPTD Puskesmas Kubu II. Inti Sari Medis, 3(1), 1-8.

Pusparani, I. D. (2016). Gambaran Gaya Hidup Pada Penderita Hipertensi Di Puskesmas Ciangsana Kecamatan Gunung Putri Kabupaten Bogor.

Putri, Idayana A., Hariyono, \& Puspita, E. Sari. (2016). Gambaran Kadar Kolesterol Total Pada Lansia, 4(1), 34-39.

Ramadhan, A. M. (2014). Pengaruh Ketepatan Terapi Dan Kepatuhan Terhadap Hasil Terapi Hipertensi Di Poliklinik Penyakit Dalam RSUP Dr. Sardjito Yogyakarta, 2(5), 301-308.

Setiawan, D., \& Felix, D. A. (2014). Tumbuhan Sakti Atasi Kolestrol. jakarta: Penerbit Buku Penebar Swadaya.

Soebroto, L. (2010). Hubungan Antara Kadar LDL Kolesterol pada Penderia
Stroke di Rumah Sakit Dr. Moewardi Surakarta, 51.

Sugiono. (2013). Metodelogi Penelitian Kuantitatif Kualitatif Dan $R \& D$. Jakarta: Alfabeta.

Suwandi, D., Sugiarto, C., \& Fenny. (2010). Perbandingan Hasil Pemeriksaan Kadar Kolesterol Total Metode Electrode-Based Biosensor Dengan Metode Spektrofotometri.

Tedjasukmana, P. (2012). Tata Laksana Hipertensi. CDK -192, 39(4), 251255.

Tryfauzi. (2016). Faktor-faktor yang Berhubungan dengan Tingkat Hipertensi di Wilayah Kerja Puskesmas Demak. Skripsi, 1-67.

Waluyo, E. M. J., Risdayanti, F., \& Nurhidayat. (2016). Tekanan Darah pada Pasien Pasca Serangan Stroke Blood Pressure in Patients with PostAttack Stroke, 16(2), 41-45.

Woro, E. T., \& Abdul, K. Z. (2012). Penggunaan Obat Pada Pasien Hipertensi Di Instalasi Rawat Inap Rumah Sakit Umum Pusat Dr. Kariadi Semarang. Majalah Farmaseutik, 8(2), 145-151.

Zaenurrohmah, D. H., \& Rachmayanti, R. D. (2017). Hubungan Pengetahuan Dan Riwayat Hipertensi Dengan Tindakan Pengendalian Tekanan Darah Pada Lansia. Jurnal Berkala Epidemiologi, 5(2),174-184.

DOI : https://doi.org/10.51544/jmn.v4i2.1543

(C) 2021 Jurnal Mutiara Ners. This is an open accessarticleunder the CC BY-SA license

Website : http://e-journal.sari-mutiara.ac.id/index.php/NERS/index 